\title{
Bioactivities of the Green Synthesized Silver Nanoparticles Reduced Using Allium cepa L Aqueous Extracts Induced Apoptosis in Colorectal Cancer Cell Lines
}

\author{
Ahmed A. H. Abdellatif $\mathbb{D}^{\mathrm{D}},{ }^{1,2}$ Amer Mahmood, ${ }^{3}$ Mansour Alsharidah $(\mathbb{D}){ }^{4}$ \\ Hamdoon A. Mohammed (D), ${ }^{5,6}$ Salman Khalaf Alenize, ${ }^{1}$ Abdellatif Bouazzaoui, ${ }^{7,8,9}$ \\ Osamah Al Rugaie $\mathbb{D}^{10}{ }^{10}$ Abdullah M. Alnuqaydan $\mathbb{D D}^{11}{ }^{11}$ Rehan Ahmad, ${ }^{12}$ \\ Mansoor-Ali Vaali-Mohammad, ${ }^{12}$ Musaad Alfayez, ${ }^{3}$ Thamer Bin Traiki, ${ }^{12}$ \\ Khalid A. Al-Regaiey, ${ }^{13}$ Asmaa T. Ali, ${ }^{14}$ Yasser A. H. Hassan, ${ }^{15}$ \\ and Maha-Hamadien Abdulla ${ }^{12}$ \\ ${ }^{1}$ Department of Pharmaceutics, College of Pharmacy, Qassim University, Qassim 51452, Saudi Arabia \\ ${ }^{2}$ Department of Pharmaceutics and Pharmaceutical Technology, Faculty of Pharmacy, Al-Azhar University, Assiut 71524, Egypt \\ ${ }^{3}$ Stem Cell Unit Department of Anatomy, College of Medicine, King Saud University, Riyadh 11472, Saudi Arabia \\ ${ }^{4}$ Department of Physiology, College of Medicine, Qassim University, Buraydah 51452, Saudi Arabia \\ ${ }^{5}$ Department of Medicinal Chemistry and Pharmacognosy, College of Pharmacy, Qassim University, 51452 Al Qassim, Saudi Arabia \\ ${ }^{6}$ Department of Pharmacognosy, Faculty of Pharmacy, Al-Azhar University, Cairo, Egypt \\ ${ }^{7}$ Department of Medical Genetics, Faculty of Medicine, Umm Al-Qura University, 21955 Makkah, Saudi Arabia \\ ${ }^{8}$ Science and Technology Unit, Umm Al-Qura University, 21955 Makkah, Saudi Arabia \\ ${ }^{9}$ Medical Clinic, Hematology/Oncology, University Hospital Regensburg, Franz-Josef-Strauß-Allee 11, 93053 Regensburg, Germany \\ ${ }^{10}$ Department of Basic Medical Sciences, College of Medicine and Medical Sciences, Qassim University, Unaizah, P.O. Box 991, \\ Al Qassim 51911, Saudi Arabia \\ ${ }^{11}$ Department of Medical Biotechnology, College of Applied Medical Sciences, Qassim University, Qassim 51452, Saudi Arabia \\ ${ }^{12}$ Colorectal Research Chair, Department of Surgery, College of Medicine, King Saud University, Riyadh 11472, Saudi Arabia \\ ${ }^{13}$ Department of Physiology, College of Medicine, King Saud University, Riyadh, Saudi Arabia \\ ${ }^{14}$ Department of Biochemistry, Faculty of Pharmacy, Nahda University, Beni-Suef 62513, Egypt \\ ${ }^{15}$ Department Psychology, College of Education, Umm Al-Qura University, 21955 Makkah, Saudi Arabia
}

Correspondence should be addressed to Ahmed A. H. Abdellatif; a.abdellatif@qu.edu.sa

Received 8 November 2021; Revised 29 December 2021; Accepted 31 December 2021; Published 4 February 2022

Academic Editor: Jun Liu

Copyright (c) 2022 Ahmed A. H. Abdellatif et al. This is an open access article distributed under the Creative Commons Attribution License, which permits unrestricted use, distribution, and reproduction in any medium, provided the original work is properly cited.

Allium cepa $L$ (A. сера) extract is frequently used as an adjuvant food in cancer treatment. We hypothesized that it contains a source of anticancer activity. There is a need to synthesize the silver nanoparticles (AgNPs) using an environment-friendly green synthesis reduction method using an aqueous extract of $A$. cepa. The AgNPs-CEPA were prepared by reduction method using the aqueous extract of A. cepa. The formed AgNPs-CEPA were characterized for their sizes and charge distribution. The AgNP-CEPA was investigated for its antioxidant and anticancer properties. Cell viability was evaluated by MTT assay. Gene expression was evaluated by real-time polymerase chain reaction (RT-PCR), and apoptosis measurement was carried out by flow cytometry in AgNP-CEPA-treated cells. The results showed a uniform size for AgNPs-CEPA of $155 \pm 2.1 \mathrm{~nm}$ with a zeta potential of $-37.3 \pm(-2.92) \mathrm{mv}$. The produced AgNPs-CEPA are biocompatible with anticancer action and a moderate level of 
antioxidant reactivity. AgNPs-CEPA showed better reducing activity for A. cepa extract compared to the AgNPs-CEPA. AgNPCEPA treatment of human colorectal cancer cell lines (HT-29 and SW620) inhibited cell proliferation and altered Bcl2 family gene expression. Moreover, exposure of cell lines to AgNPs-CEPA resulted in the significant induction of apoptosis compared to A. cepa and $\mathrm{AgNO}_{3}$. These findings indicate that AgNP-CEPA induces apoptosis by inhibiting Bcl2 family gene expression, suggesting that this formula is a promising anticancer agent for treating colorectal cancer.

\section{Introduction}

Metallic agents are the preferred chemotherapeutic therapy agents for certain malignancies. Finding new and effective chemotherapeutic drugs has led to the development of conventional and alternative therapies derived from plants. The use of nanoparticles in delivery, particularly superparamagnetic iron oxide nanoparticles (SPION), and silver nanoparticles (AgNPs), is increasing $[1,2]$. The NPs have significant roles in transport, on-site transfer, dispersion, and safe internalizations of the medication to the organs and cells [3]. Natural conjugates, metal incorporations, and tagged nanoentities are also considered efficient anticancer treatments [4-6]. Several types of NPs are reported to be anticancer agents, such as gold nanoparticles, SPION, mesoporous nanosilica, and nanosilver $[7,8]$. The biocompatible and biodegradable silver nanoparticles (AgNPs) are unique because of their chemical stability and pharmacological actions of anticancer, antiviral, antibacterial, and antifungal [9-11]. The AgNPs-based drugs have been tested against cancer cell lines [12], including human lung cancer cell lines A549 [13], KB cell lines [14], HT-29, HCT-116 and Caco-2 cell lines [15], HeLa and U937 cells [16], Hep-2 [17], prostate carcinoma cell lines (DU145), human ovarian carcinoma PC-3, SKOV3, human lymphocyte cells [18], neuroblastoma cells [19], human cervical cancer cells, prostate cancer, colon cancer COLO205 cell lines, and B16F10 mouse melanomas [20].

To avoid the cytotoxicity of chemically synthesized AgNPs to healthy cells, a green synthesis methodology can be used through utilizing the plants' extracts as the bioreduction catalyst $[21,22]$. However, several chemical processes capable of producing nanosilver are available, including chemical reduction, electrochemical method, and microorganism-based reduction of $\mathrm{AgNO}_{3}$. The green synthesis through reduction by natural compounds is obtained from a safe aqueous extract containing a plethora of compounds from A. cepa. It seemed feasible, environmentally benign, robust, cost-effective, and safer than other traditional chemical processes or physical methods [23]. The green synthesis methods were environmentally safe and reproducible [24, 25]. Its components influence yield, particle size, and growth and have different improving activities [26]. The green synthesized AgNPs with anticancer activity as albumin-coated nanoentities are also available as berberine carrier anticancer agents [27]. AgNPs synthesized from plant extracts had shell capping, contributing to the formulation's low toxicity and improved cytotoxicity to tumor cells [28].

Allium cepa $L$ (A. cepa), commonly known as an onion or bulb onion, is edible. It is a highly consumed culinary herb worldwide due to its food-specific flavor and antibacterial properties. Additionally, the plant is well-known for its multiple beneficial biological qualities related to complex sulfur compounds, thiosulfates, phenolics, and flavonoids [29]. These constituents are obtained by water and solvent extractions and steam distillation [30]. The phenolics and flavonoids, including gallic acid, ferulic acid, kaempferol, quercetin, and flavonoid glycosides, quercetin-3-gulocside, quercetin-4-gulocside, quercetin $3,4^{\prime}$-diglucoside, isorhamnetin $4^{\prime}$-glucoside, and isorhamnetin- $3,4^{\prime}$-diglucoside, were found concentrated in the outer layers of the bulb [31]. Specifically, the aqueous extract of onion has been reported for the presence of quercetin or its glycosylated derivatives as the main flavonoid constituents $(85-98 \%$ of the total flavonols in the extract), in which the quercetin aglycone (20$30 \%$ ), quercetin- $4^{\prime}$-monoglucoside and quercetin-3monoglucodise $(30-70 \%)$, and quercetin-3, $4^{\prime}$-diglucoside (5-20\%) were measured [32]. The total phenolic constituents in the aqueous extract of the plant were also measured at $47 \mathrm{mg} / \mathrm{g}$ of the extract [33]. In addition, the phenolics, gallic acid, chlorogenic acid, ferulic acid, quercetin, and kaempferol, were detected in the plant extract by the HPLC [34]. The onion bulb's antioxidant activity was determined using the autoxidation of carotene/linoleic acid coupled reaction method and the DPPH assay, confirming the bulb's positive benefits as a powerful antioxidant [35]. The potential of the A. сера has also been applied in medicine as an anticancer agent [36-38]. AgNPs suppressed MCF-7 and HeLa cell growth and inflammation. Moreover, the treatment with AgNPs can reduce allergic disorders. AgNPs could potentially reduce inflammation, allergy diseases, and bacterial infection by increasing phagocytosis [39].

The present study describes a rapid, facile, and robust green synthesis of AgNPs starting from silver nitrate. It concentrates aqueous extracts obtained from A. cepa as a powerful anticancer AgNPs. The AgNPs-CEPA were prepared by reduction method using the aqueous extract of $A$. cepa. The AgNPs-CEPA were characterized for their sizes and charge distribution. The AgNP-CEPA was investigated for its antioxidant property and tested against HT-29 cancer cell lines for its cytotoxicity and antioxidant potential.

\section{Materials and Methods}

2.1. Materials. Silver nitrate $\left(\mathrm{AgNO}_{3}\right)$ was purchased from VBBN Company (Hong Kong, China). Sulfuric acid was purchased from Severn Biotech Ltd, Kidderminster, United Kingdom. Sodium phosphate and Whatman filter paper Grade $1,11 \mu \mathrm{m}(1 \times 3 \mathrm{~cm})$, were purchased from Mumbai, Maharashtra, India. Ammonium molybdate was purchased from Sarkhej, Ahmedabad. Gujarat, India. MTT (3-(4,5dimethylthiazol-2-yl)-2,5-diphenyltetrazolium bromide) and DMSO (Dimethylsulfoxide) were purchased from 


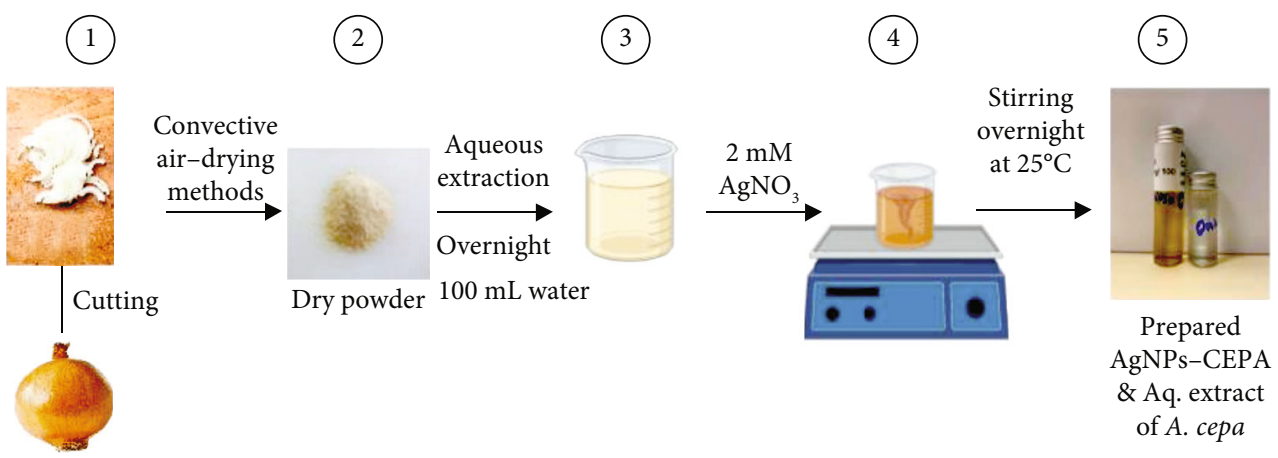

FIGURE 1: The schematic diagram for the preparation of AgNPs-CEPA.

Sigma-Aldrich (St. Louis, USA). Human colorectal cancer cell lines (HT-29 and SW620 cells) were purchased from ATCC (Manassas, Virginia, UK). Roswell Park Memorial Institute medium (RPMI-1640) (GIBCO, by Thermo Fisher Scientific, NY, USA) supplemented with $10 \%$ FBS and $1 \%$ penicillin and streptomycin and 3-(4,5-dimethylthiazol-2-yl)-2,5-diphenyltetrazolium bromide was purchased from Invitrogen Ltd 3 (Fountain Drive, Inchinnan Business Park, Paisley, PA4 9RF, UK). All cultures were incubated at $37^{\circ} \mathrm{C}$ in a humidified atmosphere of $5 \% \mathrm{CO}_{2}$. All glassware was washed using Millipore water. All chemicals were of analytical grades.

2.2. Plant Materials and Preparation of the Aqueous Extract of A. cepa. The onion (Allium cepa $L, A$. cepa) was purchased from the local market in Buraydah, Al Qassim, Saudi Arabia, and identified by the local botanists at the Department of Plant Production and Protection, College of Agriculture, Qassim University. A. cepa bulbs were sliced into pieces of $\sim 4 \mathrm{~mm}$ thickness. The $A$. cepa pieces were dried in an oven at $50^{\circ} \mathrm{C}$ temperatures for three days using the convective air-drying method. The aqueous $A$. cepa extract was prepared by continuous stirring of $1 \mathrm{gm}$ dried $A$. серa with $100 \mathrm{ml}$ of distilled water at $25 \pm 1^{\circ} \mathrm{C}$ for $4 \mathrm{~h}$. The aqueous extract was purified using a Whatman filter paper Grade 1, $11 \mu \mathrm{m}(1 \times 3 \mathrm{~cm})[40]$.

2.3. Preparation of the AgNPs-CEPA. The AgNP-CEPA was prepared according to the previously reported method with some modification for better results [41]. Briefly, $1 \mathrm{mM}$ stock solution of silver nitrate $\left(\mathrm{AgNO}_{3}\right)$ was prepared, stirred with the scheduled aqueous extraction of $A$. cepa using a multiple-stirrer digital magnetic stirrer (VELP Scientifica Srl, Italy). The stirring at $600 \mathrm{rpm}$ has been optimized at room temperature at $25 \pm 1^{\circ} \mathrm{C}$. The synthesis of AgNPs (AgNPsCEPA) was confirmed by observing a color change from colorless to yellowish. Then, the synthesized nanoparticles were collected and stored in a dark place away from light.

\subsection{Characterization of AgNPs-CEPA}

2.4.1. Size and Charge. The size and charge of the produced AgNPs-CEPA were measured using a Malvern Zetasizer Nano, Malvern Instruments GmbH (Herrenberg, Germany). Data were presented as the average of the three different measurements of the same AgNPs. The surface charge of AgNPs-CEPA was determined by zeta potential measure- ments with the same equipment. AgNP-CEPA was put through a laser beam of $623 \mathrm{~nm}$, and the angle was adjusted to $90^{\circ}$ at $25^{\circ} \mathrm{C}[42,43]$. The results presented are the average measurements of the runs with standard deviation.

2.4.2. Ultraviolet-Visible Spectroscopy. Ultraviolet-visible (UV-vis) spectrophotometry (Jasco, UV-630, Japan) was used to analyze the $A$. cepa extract and AgNPs-CEPA. AgNPs were put through a laser lamp and the angle was $90^{\circ}$ at wavelengths ranging from 200 to $800 \mathrm{~nm}$. The absorption range of reaction solutions was reported as a function of reaction time. We used distal water as a reference or blank, and then, we put the samples which contained particles in the instrument $[44,45]$.

2.4.3. Fourier-Transform Infrared Spectroscopy. The study was aimed at proving the formation of AgNPs-CEPA. FTIR measurements were used to analyze the compatibility of biomolecules associated with AgNP formation. It was measured with a Bruker Tensor 27 FTIR spectrophotometer (Varian Company model: 640-IR, Australia) [42]. The FTIR spectra were recorded, and the absorption peaks were observed at $400-4000 \mathrm{~cm}^{-1}$.

2.4.4. SEM Analysis. Scanning electron microscopy (FESEM, supra 55-Carl Zeiss, Germany) was used to study the morphology and size of the synthesized nanoparticles AgNPsCEPA [44].

2.5. Antioxidant Activity Screening. As a comparable assay, three in vitro methods were conducted to evaluate the antioxidant activity of the A. cepa extract and formulated AgNPs of the extract (AgNPs-CEPA). The procedures were performed in triplicate for all experiments, and the antioxidant activity of CEPA and AgNPs-CEPA was calculated using standard calibration curves of Trolox for each method.

2.5.1. Total Antioxidant Capacity (TAC). Total antioxidant capacity (TAC) of the CEPA and AgNPs-CEPA was conducted according to Aroua et al. [46]. $200 \mu \mathrm{l}$ of all samples (final concentration $200 \mu \mathrm{g}$ ) was added to the freshly prepared acidic molybdate reagent $(2 \mathrm{ml})$. The mixture was then vigorously shaken and heated on the water bath for $90 \mathrm{~min}$ at $85^{\circ} \mathrm{C}$ and cooled to room temperature $\left(25^{\circ} \mathrm{C}\right)$. The absorbance of the blue color that arises was measured at $695 \mathrm{~nm}$, 


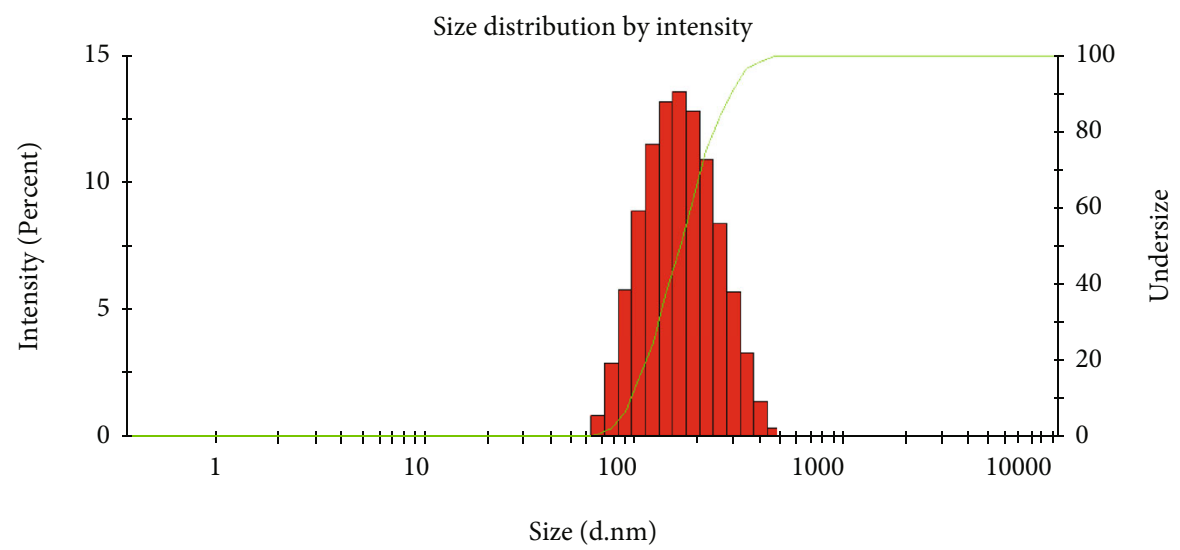

(a)

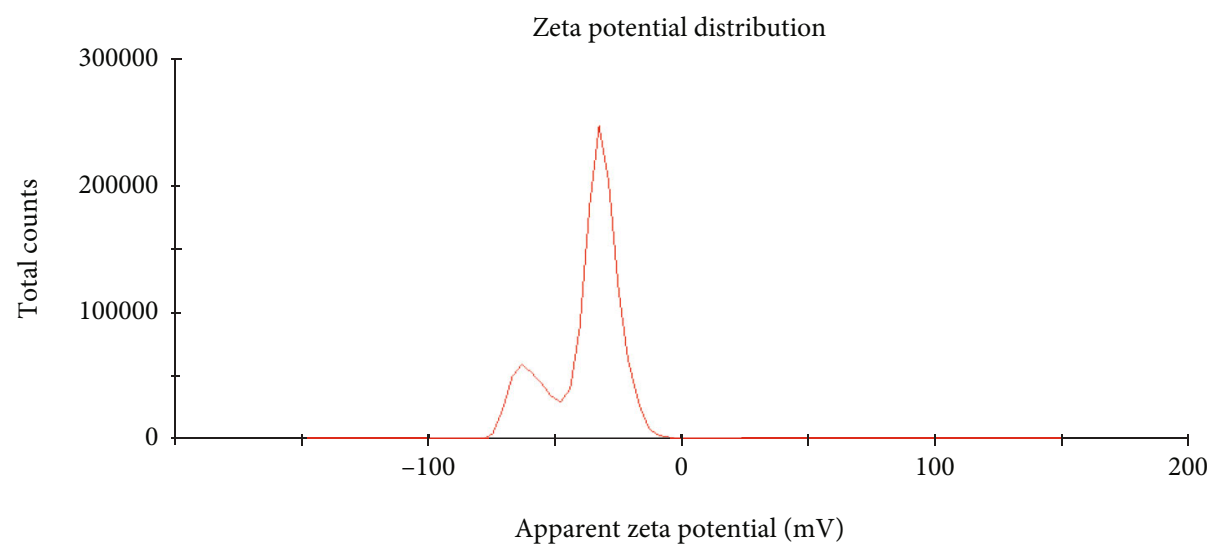

(b)

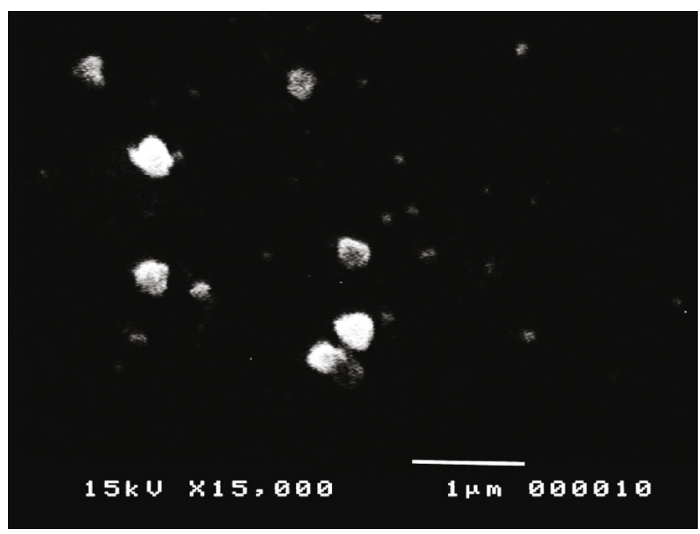

(c)

FIGURE 2: Nanoparticle characterization of the reduced AgNPs using A. cepa: (a) size distribution by mean diameter as determined using DLS, (b) apparent zeta potential as determined by DLS, and (c) SEM examination analysis.

and the total antioxidant activity of the samples was calculated using the Trolox standard calibration curve.

2.5.2. DPPH Scavenging Activity (DPPH-SA). DPPH scavenging activity (DPPH-SA) was conducted according to Mohammed et al. [47] with minor modification. The DPPH in a concentration of $300 \mu \mathrm{M}(1 \mathrm{ml})$ was added to $1 \mathrm{ml}$ of $A$. cepa and AgNPs-CEPA (final concentration $200 \mu \mathrm{g}$ ). The mixture was vortexed and stood in a dark place for $30 \mathrm{~min}$ at room temperature to develop the violet color which mea- sures spectrophotometrically at $517 \mathrm{~nm}$. The DPPH-SA activity of the prepared nanoparticles AgNPs-CEPA and $A$. cepa aqueous extract was measured in equivalents to the Trolox using its calibration curve.

2.5.3. DPPH Scavenging Activity (DPPH-SA). In the ferric reducing antioxidant power (FRAP) method, the FRAB reagent was prepared according to the process of Benzie and Strain [48]. Accurately, $2 \mathrm{ml}$ of the FRAB reagent was added to $0.1 \mathrm{ml}$ of the samples (final concentration $200 \mu \mathrm{g}$ ). The mixture was 


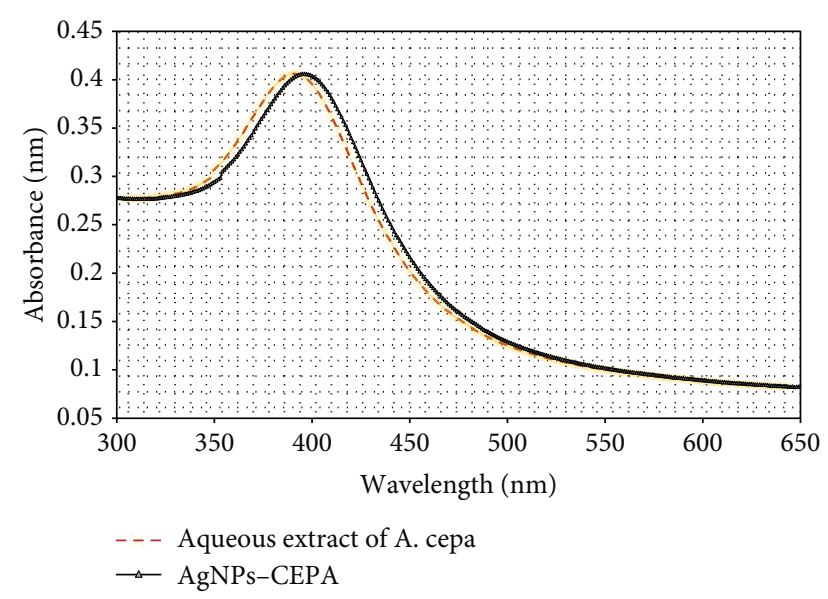

Figure 3: UV-vis absorption spectrum of the produced AgNPsCEPA and aqueous extract of A. cepa.

incubated for $30 \mathrm{~min}$ at room temperature $\left(25^{\circ} \mathrm{C}\right)$, and the absorbance was recorded at $593 \mathrm{~nm}$. The FRAP of the prepared nanoparticles AgNPs-CEPA and A. cepa were measured in equivalents to the Trolox using its calibration curve.

2.6. Cell Culture. Human colorectal cancer cell lines (HT-29 and SW620 cells) were cultured in Roswell Park Memorial Institute medium (RPMI-1640) (GIBCO, by Thermo Fisher Scientific, NY, USA) supplemented with $10 \%$ FBS and $1 \%$ penicillin and streptomycin. All cultures were incubated at $37^{\circ} \mathrm{C}$ in a humidified atmosphere of $5 \% \mathrm{CO}_{2}$.

2.7. Cell Viability Assay. Cell viability was quantified using the MTT assay as previously described method [35]. Cells $\left(5 \times 10^{3}\right.$ per well) were plated in a 96-well plate (Corning, $\mathrm{NY}$, USA). $24 \mathrm{~h}$ after incubation, the cells were set as the control and incubated with an aqueous solution of $A$. cepa extract, $\mathrm{AgNO}_{3}$, and AgNPs-CEPA with varying concentrations $(5-100 \mu \mathrm{g} / \mathrm{ml})$ for $24 \mathrm{~h}$. AgNPs-CEPA were incubated in the form of an aqueous solution as originally prepared. The A. cepa dried extract was suspended in the Millipore water before incubation with cells. $10 \mu \mathrm{l}$ of 3-(4, 5-dimethylthiazol-2-yl)-2,5-diphenyltetrazolium bromide (MTT) $(5 \mathrm{mM})$ solution was mixed with the cells and incubated for $2-3 \mathrm{~h}$ at $37^{\circ} \mathrm{C}$ in a $5 \% \mathrm{CO}_{2}$ atmosphere. $100 \mu \mathrm{l}$ of DMSO was put into each well, and the crystals were dissolved with careful pipetting. A Synergy 2 multimode microplate reader was used (Biotech, VA, USA). Each experiment was performed three times.

2.8. Flow Cytometry for Apoptosis. Apoptosis and necrosis were determined in the same manner as previously described [35]. HT-29 and SW620 cells were seeded in a 6-well plate at a density of $1 \times 10^{5} /$ well for $24 \mathrm{~h}$. The next day, cells were treated with different concentrations of aqueous solutions of A. cepa extract, $\mathrm{AgNO}_{3}$, and AgNPs-CEPA for $24 \mathrm{~h}$. The cells were extracted and washed twice with ice-cold PBS after being harvested. Apoptosis detection was conducted using an Annexin V/Dead cell apoptosis kit (Cat\# V13242, Thermo Fisher Scientific Inc., Waltham Massachusetts) to detect cell death. The pellet was resuspended in 1X binding buffer and treated for 15 minutes in the dark at room temperature with Annexin V-FITC (5l) and 11 propidium iodide. The data analysis was collected using Cell Quest Pro Ver 6.0 BD FACS CALIBUR (BD Biosciences, San Jose, CA USA).

The primer sequences are as follows: Bax, F: CCC TTT TGC TTC AGG GTT TC and R: TCT TCT TCC AGA TGG TGA GTG; Bcl-2, F: ACG AGT GGG ATG GGG GAG ATG TG and R: GCG GTA GCG GCG GGA GAA GTC; Bcl-xL, F: CTG AAT CGG AGA TGG AGA CC and R: TGG GAT GTC AGG TCA CTG AA; and Mcl-1, F: AGA AAG CTG CAT CGA ACC AT and R: CC AGC TCC TAC TCC AGC AAC.

2.9. Physical Stability. A three-month storage period at $25.0 \pm 0.5^{\circ} \mathrm{C}$ and $4.0 \pm 0.5^{\circ} \mathrm{C}$ was used to evaluate the physical stability of the prepared AgNPs-CEPA. The physical parameters such as color, shape, particle size, and zeta potential were measured before and after storage to determine their stability [49].

2.10. Statistical Analysis. All experiments were performed in triplicate, and statistical means and standard errors were calculated. The statistical significance of differences between values of the treated and untreated (control) groups was evaluated by two-way ANOVA. The differences with $p<$ 0.05 were considered significant. ${ }^{*} p \leq 0.05$ and ${ }^{* *} p \leq 0.01$ denote statistically significant differences.

\section{Results}

The prepared AgNPs utilizing the aqueous extracts of the $A$. cepa showed a color change from dark green to light green, which indicated the formed nanosilver configuration due to Surface Plasmon Resonance (SPR) excitations of the AgNPs as reflected in the UV-vis spectrum of the product. The color change of the aqueous extract to the synthesized AgNPs confirmed the successful synthesis of AgNPs. For A. cepa, the aqueous extract color is white and it has been changed to olive yellowish color, which indicates AgNPCEPA formation (Figure 1). The differential light scattering (DLS) recorded uniform AgNPs with symmetrical peaks of size $155 \pm 2.1 \mathrm{~nm}$ (Figure 2(a)). The zeta potentials of AgNPs-CEPA were also measured in phosphate buffer at $\mathrm{pH}$ 7. The AgNPs-CEPA had negative surface charge values of $-37.3 \pm 2.92 \mathrm{mv}$ (Figure 2(b)). All PDIs (polydispersity indices) were below 0.145 , representing a stable colloidal system. The SEM showed AgNPs-CEPA with cubic shapes with an average diameter of 150-250 nm (Figure 2(c)).

3.1. Ultraviolet-Visible Spectroscopy. The results showed an absorption spectrum of $A$. cepa at $390 \mathrm{~nm}$ (Figure 3). Moreover, the UV-vis absorption spectrum of the produced AgNPs-CEPA showed an absorbance peak at $398 \mathrm{~nm}$ due to the excitation of SPR in the formed AgNPs. One of the most essential features in the optical absorbance spectra of metal nanoparticles is SPR, which is due to collective electron oscillation around the surface mode of the particles [41]. A single SPR band in the absorption spectra of the produced AgNPs indicates its spherical shape [50]. 


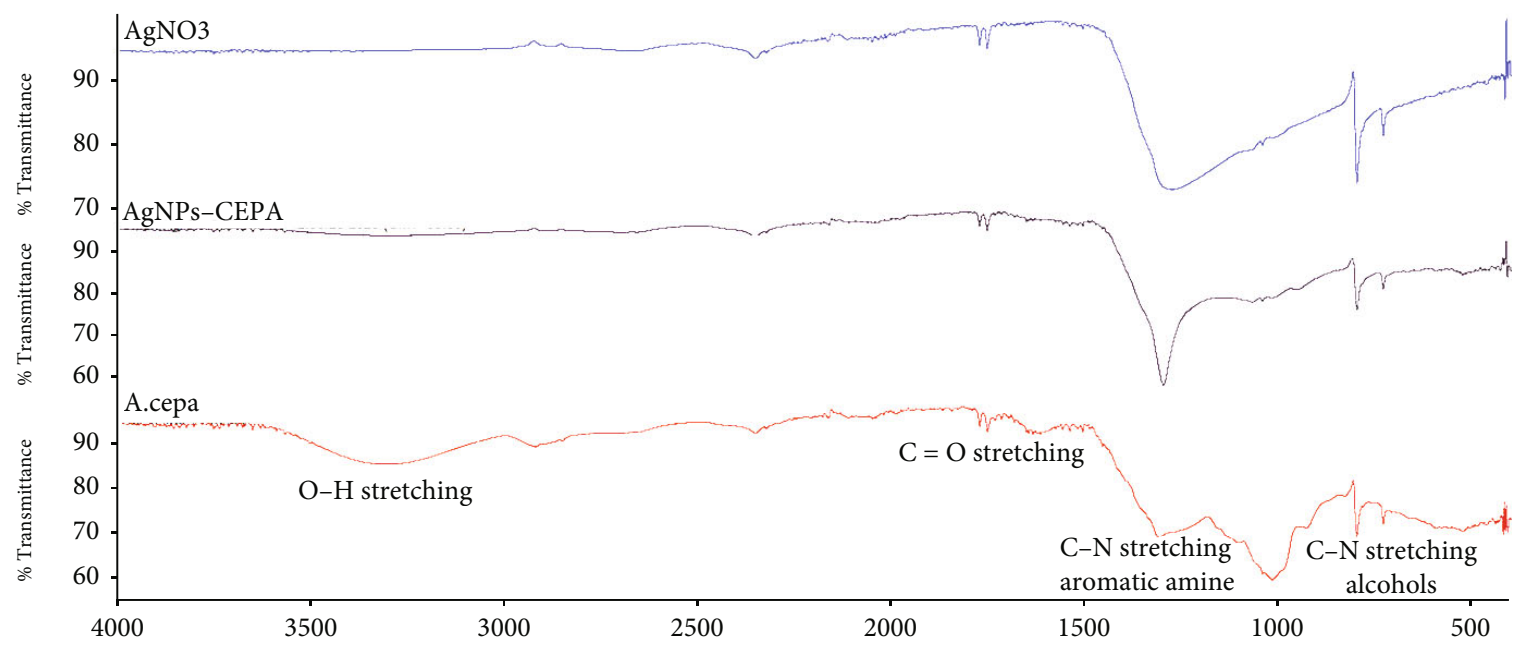

FIGURE 4: FT-IR spectrum of the biosynthesized silver nanoparticles AgNPs-CEPA.

TABle 1: The antioxidant activities for A. cepa extract and synthesized silver nanoparticles AgNPs-CEPA using different antioxidant agents.

\begin{tabular}{lccc}
\hline Name & TAA & DPPH-SA & FRAP \\
\hline A. cepa & $55.49 \pm 0.91$ & $2.23 \pm 0.36$ & $14.78 \pm 0.20$ \\
AgNPs-CEPA & $58.85 \pm 4.39$ & $1.91 \pm 0.20$ & $13.37 \pm 0.17$ \\
\hline
\end{tabular}

All the measurements were conducted in triplicate; mean and standard deviations were calculated. TAA: total antioxidant activity in mg Trolox equivalents per gram of the dried plant powder; FRAP: ferric reducing antioxidant power in $\mathrm{mg}$ Trolox equivalent per gram of the dried plant powder; DPPH-SA: 2,2-diphenyl-1-picrylhydrazyl-scavenging activity in mg Trolox equivalent per gram of the dried plant powder.

3.2. Fourier-Transform Infrared Spectroscopy. As shown in Figure 4, for AgNPs-CEPA, A. cepa, and $\mathrm{AgNO}_{3}$, the FTIR showed shared similar peaks with their AgNP-CEPA peaks between 3000 and $3600 \mathrm{~cm}^{-1}$ which indicates $\mathrm{O}-\mathrm{H}$ stretching and $\mathrm{C}-\mathrm{H}$ is bending at $1385-1380 \mathrm{~cm}^{-1} \mathrm{~cm}^{-1}, \mathrm{C}-\mathrm{N}$ is stretching at $1000-1400 \mathrm{~cm}^{-1}$, and $\mathrm{C}=\mathrm{O}$ is stretching at 1750 $1735 \mathrm{~cm}^{-1}$.

3.3. Antioxidant Activity. The data mentioned in Table 1 described the antioxidant activity of the A. cepa extract and formulated AgNPs-CEPA. The results showed insignificant variation between the $A$. cepa extract and its prepared nanoparticles in the TAA and DPPH-SA. However, FRAP showed better reducing activity for the $A$. cepa extract compared to the prepared AgNP-CEPA nanoparticles.

3.4. Cell Cytotoxicity. Human colorectal cancer cell line HT29 cells were treated with different concentrations of the aqueous solutions of $A$. cepa extract, $\mathrm{AgNO}_{3}$, and AgNPsCEPA for $48 \mathrm{~h}$. AgNP-CEPA was found to inhibit \% viability of HT-29 in a dose-dependent manner starting at $20 \mu \mathrm{M}$ (Figure 5(a)). We used another colorectal cancer cell line of metastatic origin, SW620 cells, to confirm this finding. Exposing SW620 cells with A. cepa extract, $\mathrm{AgNO}_{3}$, and AgNPs-CEPA resulted in significant dose inhibition of per- cent viability starting at $10 \mu \mathrm{M}$ (Figure 5(b)). $\mathrm{AgNO}_{3}$ alone was found to have some inhibitory effect at higher concentrations $(100 \mu \mathrm{M})$ in both cell lines. These findings thus demonstrate that AgNP-CEPA has anticancer potential in human colorectal cancer cell lines [51].

3.5. Quantitative PCR. HT-29 and SW620 cells were treated with different concentrations of $A$. cepa extract, $\mathrm{AgNO}_{3}$, and AgNPs-CEPA for $48 \mathrm{~h}$. We looked at the apoptosis and antiapoptosis marker genes by quantitative RT-PCR. We clearly showed that $\mathrm{AgNO}_{3}$ and AgNPs-CEPA downregulate antiapoptotic genes BCL2 and BCL-Xl and increase apoptotic gene BAX significantly. All genes were normalized to the expression of GAPDH that was used as the housekeeping gene (Figure 6).

We also investigated the effect of $A$. cepa extract, $\mathrm{AgNO}_{3}$, and AgNPs-CEPA on inducing apoptosis by flow cytometry in two human colorectal cancer cell lines. Treatment of HT29 with different concentrations of AgNPs-CEPA was associated with increased cell death. As shown in Figures 7(a) and 7(b), AgNPs-CEPA induced 29.5 and 88.6\% apoptosis at 10 and $20 \mu \mathrm{g} / \mathrm{ml}$ concentrations, respectively, compared to control cells $(1.3 \%)$. A. cepa extract was found to induce $3.8 \%$ and $10.7 \%$. Treatment with $\mathrm{AgNO}_{3}$ resulted in $1 \%$ and $3.12 \%$ apoptosis induction. Furthermore, the effect of AgNP-CEPA-mediated cell death was studied in metastatic colorectal cancer cell lines SW620. AgNP-CEPA treatment of SW620 cells induced $68.6 \%$ and $74 \%$ total cell death compared to $1.07 \%$ in the control cells at 10 and $20 \mu \mathrm{g} / \mathrm{ml}$ concentrations (Figures 8(a) and 8(b)). Recent strategies for anticancer development target-specific biomarkers are required for cancer cell survival, thereby inducting cell apoptosis and thus affecting cancer cells selectively with minimum effect on normal cells. Among these targets is the antiapoptotic protein $\mathrm{Bcl} 2$ family. AgNP-CEPA treatment of HT-29 and SW620 cells resulted in a significant increase in apoptosis/cell death compared to A. cepa and AgNPsCEPA. These findings thus indicate that AgNP-CEPA effectively inhibits cell proliferation and at the same time induces apoptosis by altering $\mathrm{Bcl} 2$ family gene expression. 


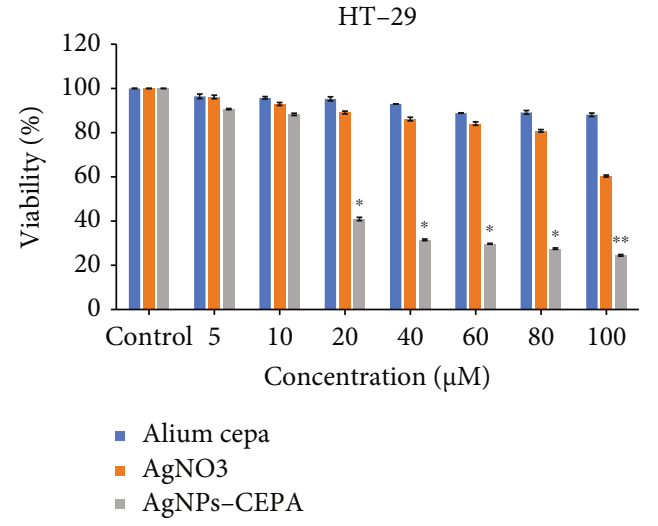

(a)

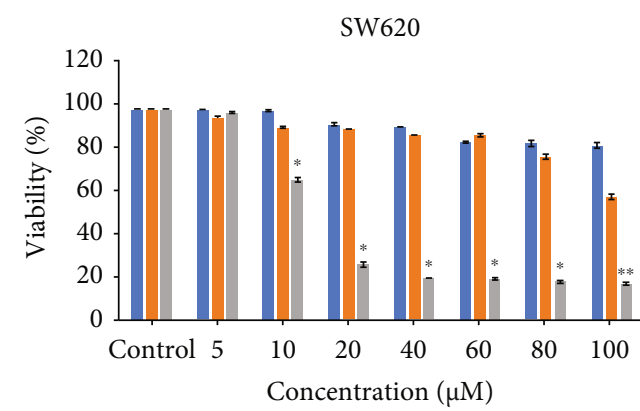

- Alium cepa

- $\mathrm{AgNO} 3$

- AgNPs-CEPA

(b)

Figure 5: Cell viability assay of two different cancer cell lines. (a) Anticancer activity of $A$. cepa extract, AgNO ${ }_{3}$, and AgNPs-CEPA in HT-29 cells and (b) anticancer activity of $A$. cepa extract, $\mathrm{AgNO}_{3}$, and AgNPs-CEPA in SW620 cells. ${ }^{*} p \leq 0.05$ and ${ }^{* *} p \leq 0.01$ denote statistically significant differences.
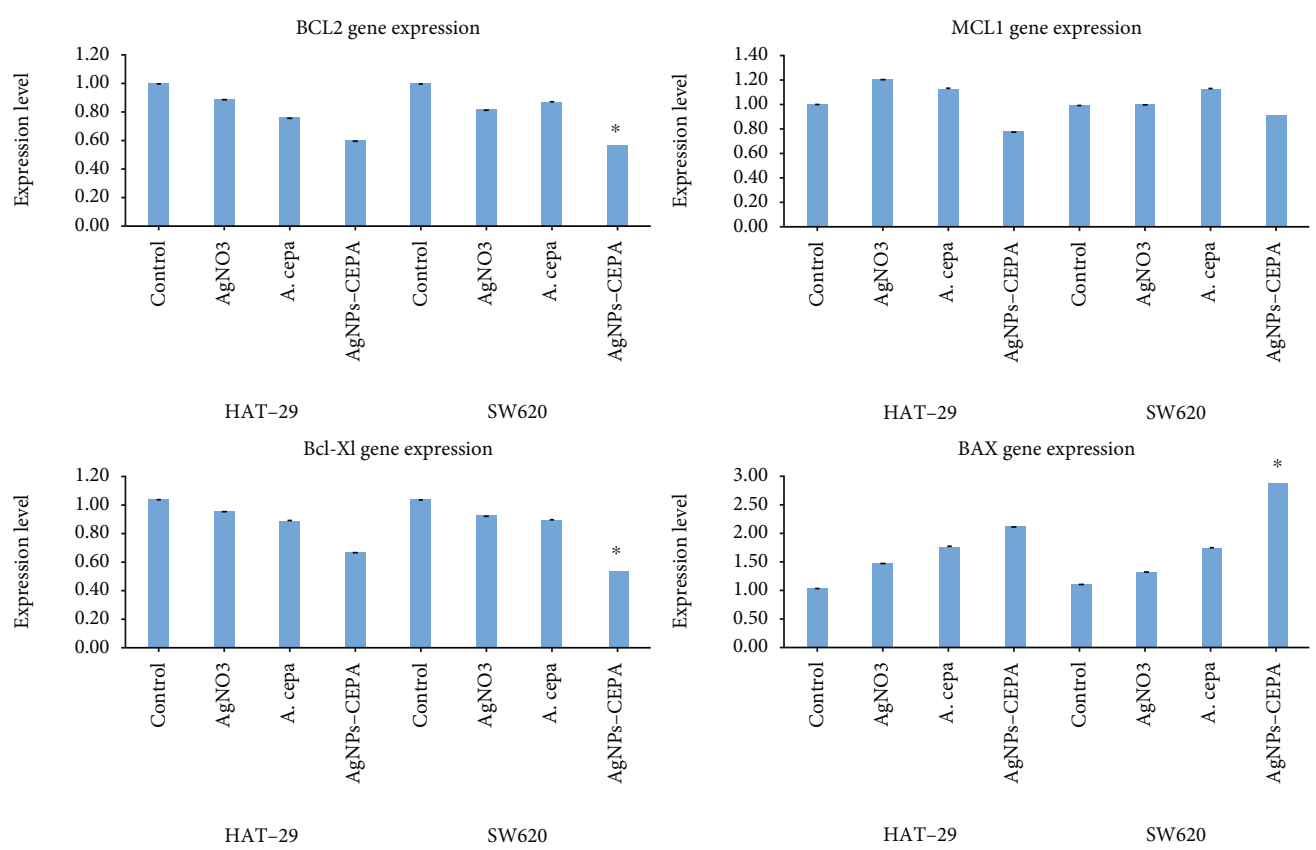

FIGURE 6: Quantitative real-time PCR gene expression analysis of proapoptosis and antiapoptotic genes. ${ }^{*} p \leq 0.05$ denotes statistically significant differences.

3.6. Physical Stability. The physical stability of all prepared AgNPs-CEPA was investigated for three months at $25 \pm 1$ ${ }^{\circ} \mathrm{C}$ and $4.0 \pm 1^{\circ} \mathrm{C}$, respectively. The results revealed no difference in color or morphology between the two conditions studied. Furthermore, the prepared AgNPs-CEPA showed a nonsignificant ( $p \geq 0.05$; ANOVA/Tukey) change in particle sizes, PDI, and zeta potentials, which agreed with the results obtained by Fernando et al. [52].

\section{Discussion}

The study was aimed at using the aqueous extract of the $A$. cepa for reducing $\mathrm{AgNO}_{3}$ to AgNPs-CEPA and investigate the antioxidant and anticancer activities. The synthesis of
AgNPs-CEPA was confirmed as the color changed from colorless to yellowish color. These results agreed with those reported previously by Safaepour et al. [53], who reported the same color change from colorless to dark brown, indicating the formation of AgNPs. Percent of phenolics, flavonoids, quercetin aglycone, and calcium in the peel of $A$. cepa can play a role in forming AgNPs. A. cepa has been reported to possess dietary fibers and antioxidant activities. The brown skin of an onion peel extract contains different phytochemical constituents such as dietary fiber, phenolics, and flavonoids. In the development and stabilization of AgNPs, this phytochemical plays a significant role [31]. Thus, A. cepa (onion) is encouraged as a good and protective diet against cancer. In this research, $A$. cepa extract was used 


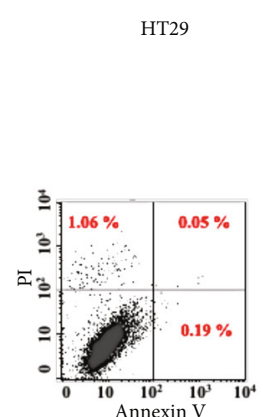

Control
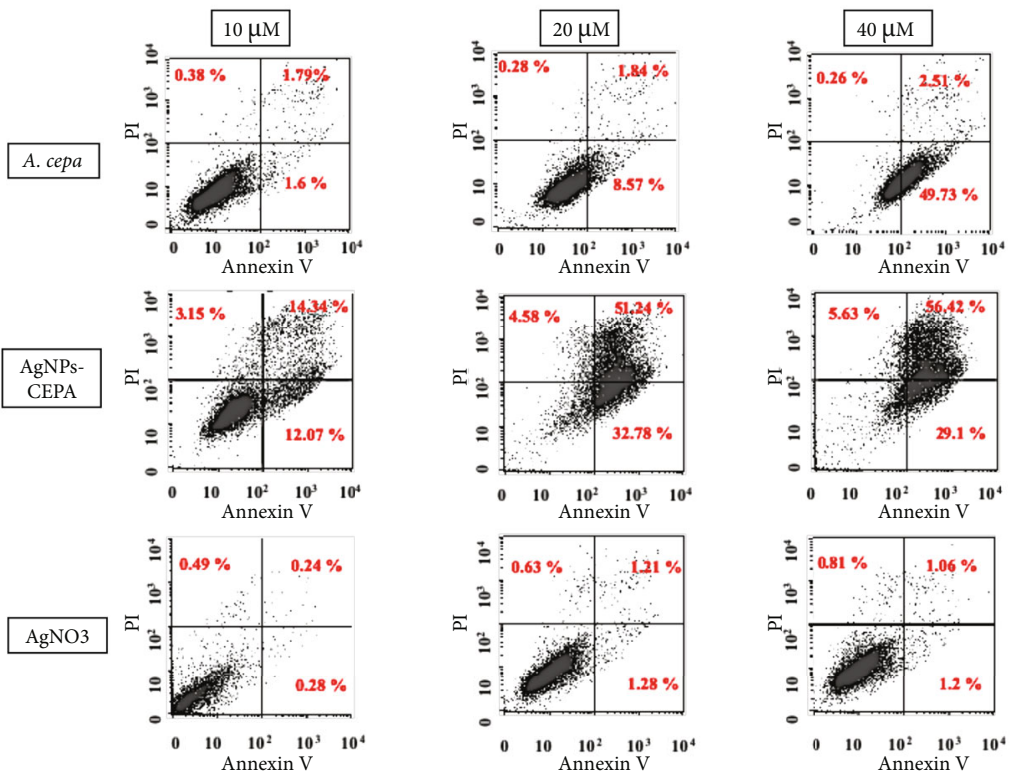

(a)

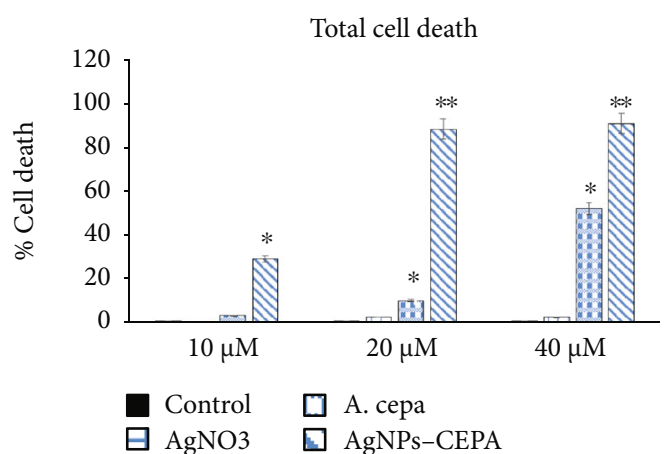

(b)

Figure 7: Apoptosis assay by flow cytometry of HT29 cancer cell lines with or without $\mathrm{AgNO}_{3}, A . c e p a$, and AgNPs-CEPA. ${ }^{*} p \leq 0.05$ and ${ }^{* *} p \leq 0.01$ denote statistically significant differences.

to reduce Ag+ ions in the aqueous solution of silver nitrate (equation (1)). In addition, a color transition signaling is due to the successful formation of AgNPs. The shift in the state of matter from the molecular level to the nanoscale includes a change in color due to the stimulation of SPR vibrations, which occurs due to the transition.

$$
\mathrm{Ag}^{+}+e^{-}=\mathrm{Ag}^{0}
$$

In the current preparation, the particle sizes were observed to increase, reflecting various involved factors' roles. They were validated by the color changes in the preparation recorded with the UV-vis absorption spectra of the colored prepared solutions. Fuku et al. [54] outlined that the colors of all plasmonic NPs can be scientifically altered, owing to changes in the SPR absorption wavelength by varying the size and morphology of the particles. The AgNPsCEPA had a size of $155 \pm 2.1 \mathrm{~nm}$ and a negative surface charge $-37.3 \pm 2.92 \mathrm{mv}$ with a color change from colorless to yellowish brown. The high negative zeta potential indi- cated that the particles are of the highest electrically stabilized nature to resist aggregation. Similar results were reported by Moraes et al. [55], as the size, PDI, and zeta potential of nanoparticles are parameters that indicate the stability of NPs. The surface charges upon NPs play significant roles in the stabilization of the NPs, whereas the degree of zeta potential is an investigative parameter of the colloidal stability of the system [56]. The PDI was 0.145 , supposedly indicating the (near) homogeneity of the particles' sizes in the sample of the nanocolloid. It was reported that PDIs lower than 0.2 are ideal because the size distribution of NPs falls within a small range of sizes [57]. A significant technique used to validate the formation of metal nanoparticles in an aqueous solution is UV-visible spectroscopy. UV-vis absorption spectrum showed an absorbance peak at 390 and $398 \mathrm{~nm}$ for $A$. cepa and AgNPs-CEPA, respectively. The appearance in the absorption spectra of generated AgNPs of a single SPR band indicates their spherical form [41]. The FTIR absorption spectroscopy confirmed the presence of $A$. cepa 


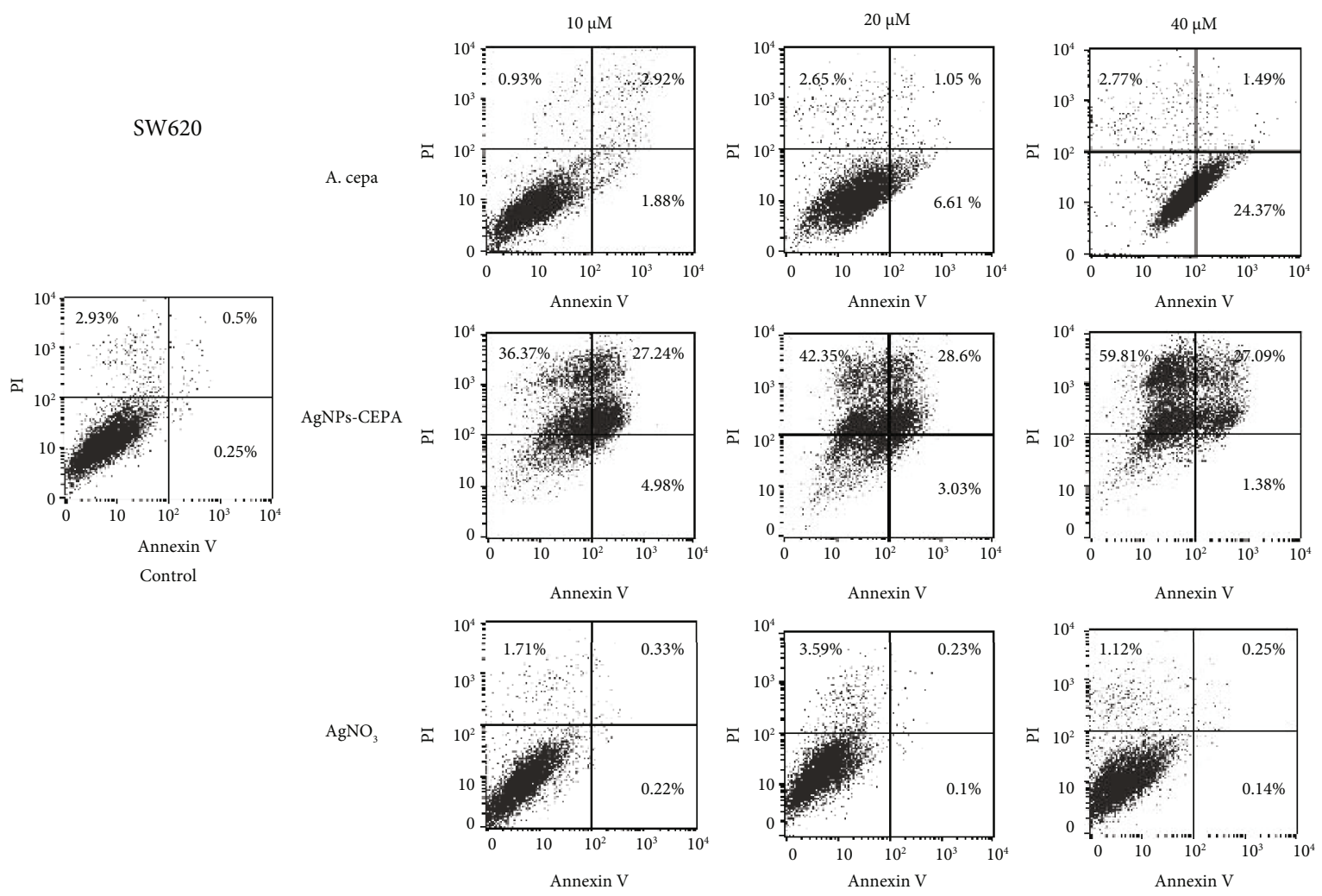

(a)

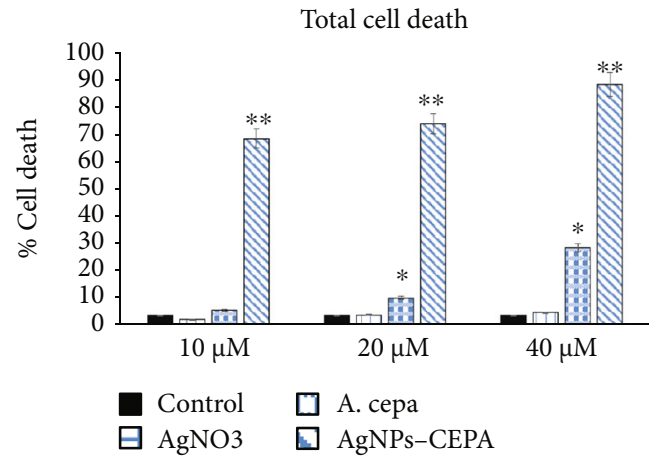

(b)

Figure 8: Apoptosis assay by flow cytometry of HT29 cancer cell lines with or without $\mathrm{AgNO}_{3}, A$. cepa, and AgNPs-CEPA. ${ }^{*} p \leq 0.05$ and ${ }^{* *} p \leq 0.01$ denote statistically significant differences.

covered silver colloid of the present synthesis. The FTIR bands showed the typical peaks for A. cepa for the surface related to $\mathrm{Ag}^{0}$. In an earlier study, Sunkar and Nachiyar [58] also confirmed IR absorption peaks in the ranges of $3510 \mathrm{~cm}^{-1}$ and $1636 \mathrm{~cm}^{-1}$ for the AgNP-citrate preparation by trisodium citrate reduction method.

The band at $3424 \mathrm{~cm}^{-1}$ correlates to $\mathrm{O}-\mathrm{H}$ extending $\mathrm{H}$ bonded alcohols and phenols. Peaks of $2921 \mathrm{~cm}^{-1}$ correlate to carboxylic acids with $\mathrm{O}-\mathrm{H}$ stretch. $\mathrm{N}-\mathrm{H}$ bend primary amines correspond to the assignment at $1625 \mathrm{~cm}^{-1}$. C-N stretching of the aromatic amine group corresponds to the highest at $1387 \mathrm{~cm}^{-1}$, and the bands detected at 1061 and $971 \mathrm{~cm}^{-1}$ relate to C-N stretching alcohols, carboxylic acids, ethers, and esters [41]. Therefore, peaks were presented for proteins and metabolites such as terpenoids with functional aldehydes, ketones, alcohols, and carboxylic acids accompanying the synthesized AgNPs [59]. Moreover, the amino acid residue carbonyl group has a greater capacity to bind metal, suggesting that proteins can keep molecules in groups and stabilize AgNPs in the aqueous medium [60].

The results obtained for the antioxidant activity of the aqueous A. cepa extract and the formulated AgNP-CEPA particles demonstrated potential and similar reducing power for the molybdenum (VI) to molybdenum (V) in the TAA with $55.49 \pm 0.91$ and $58.85 \pm 4.39 \mathrm{mg}$ Trolox equivalents per gram of the dried plant powder, respectively. The scavenging activity of the extract and AgNP-CEPA particles also showed nonsignificant variations in the DPPH-SA at 2.23 \pm 0.36 and $1.91 \pm 0.20 \mathrm{mg}$ Trolox equivalents per gram of the dried plant powder, respectively. However, results 
obtained for FRAP assay showed a little higher activity for the onion extract compared to AgNP-CEPA particles at $14.78 \pm 0.20$ and $13.37 \pm 0.17 \mathrm{mg}$ Trolox equivalents per gram of the dried plant powder, respectively. The overall antioxidant results demonstrated in Table 1 revealed that AgNP-CEPA nanoparticles retained the antioxidant power of the plant extract.

However, the AgNP-CEPA was more toxic compared to A. cepa, and this may be due to the high toxicity of $\mathrm{AgNO}_{3}$. Because antioxidant and anticancer are two different events, anticancer activity indeed depends on antioxidant activity. Still, other pathways influence the viability, like apoptosis which different stress factors can induce. Therefore, it is possible that the antioxidant activity does not correlate with the anticancer activity which is already supported in previous publications [61]. The prospects of AgNPs synthesized from the A. cepa are an anticancer agent owing to its potent antioxidant potential due to high contents of phenolics and flavonoids [62]. They also have strong reducing possibilities due to various sulfur compounds in the aqueous extract, together with the elemental silver at a nanosized scale. Moreover, the shell capping of the chemical components of the $A$. cepa made the combination a potent candidate for anticancer evaluation [23]. Gomaa reported anticancer activity of AgNPs synthesized by A. cepa extract against various cancer cell lines from the breast, hepatocellular, and colon [41]. We are writing here for the first time the anticancer property of AgNPs synthesized with $A$. cepa extract against colorectal cancer cell (CRC) lines from different stages, i.e., adenocarcinoma CRC cell line (HT-29) and metastatic CRC cell line (SW620). We also increased the concentration of AgNPs from $0.1 \mathrm{mM}$ by Gomaa to $1 \mathrm{mM}$ with safe effects on cells.

Cancer cell survival is regulated by genes that regulate cell proliferation and apoptosis. Bcl2 family proteins are divided into antiapoptotic proteins, $\mathrm{Bcl} 2$ and $\mathrm{BclxL}$, and proapoptotic proteins, Bax, Bak, and Bid, which play a vital role in the apoptosis regulation [63]. Cancer cells' fate is determined by the balance of proapoptotic and antiapoptotic proteins. Bcl2 and BclxL overexpression inhibits apoptosis and enhances cancer cell growth, making them intriguing targets for cancer therapy development. This study found that AgNPs-CEPA inhibited the Bcl2 and BclxL gene expression in a dose-dependent manner in colorectal cancer cells as a novel result for future targeting of cell $\mathrm{Bcl} 2$ and $\mathrm{BclxL}$ overexpression. As a result, the suppression of $\mathrm{Bcl} 2$ and BclxL increases the vulnerability of cancer cells to apoptosis.

Further, treatment with AgNPs-CEPA increases proapoptotic gene expression like Bax. AgNPs-CEPA could be effective as an anticancer agent by targeting the Bcl2 family protein. Blocking cell proliferation is primarily mediated by apoptosis that plays an important role in fighting cancer [64]. As a result, apoptosis is a common target for cancer therapy techniques. In this study, we found that AgNPsCEPA could trigger a significant increase in apoptosis in HT-29 and SW620 cells compared to control and A. cepa extract alone. Induction of apoptosis by anticancer therapy is the most known way to kill cancer cells. AgNP-CEPA was significantly effective in inducing apoptosis by targeting Bcl2 family proteins which holds promise as anticancer ther- apeutics. Moreover, the higher death of cells treated with AgNPs-CEPA is expected due to the synergistic effect produced due to the reduction of $A$. cepa to $\mathrm{Ag}^{0}$ [65-67]. The size used in cell biology is considered a larger size. According to research, using the smallest feasible nanoparticles may not be the greatest idea. The larger particles demonstrated higher resistance against external influences than smaller NPs. The particle size substantially impacted the in vitro toxicity, as samples with a larger particle size preserved more of their activity against mammalian cells [68]. Moreover, nanoparticle size and shape are known to affect biological activity $[69,70]$. AgNPs, according to the findings of this study, could be a highly effective cancer therapy for a variety of cancers, as well as an alternate treatment for inflammation prevention by increasing autophagy [71].

\section{Conclusion}

The green synthesized AgNPs with their unique physical properties provide an alternative for the chemically produced AgNPs. The synthesized AgNPs using an aqueous extract of $A$. cepa were successfully synthesized with uniform size and good stability. The nanoparticles also showed antibreast cancer activity and could further be developed as a template for other anticancer actions. AgNP-CEPA inhibits cell viability and reduced antiapoptotic genes. AgNP-CEPA has anticancer properties that could be used to treat colorectal adenocarcinoma and mCRC. These results are very promising in the field of nanoparticles for anticancer activity. We encourage using onion and AgNPs-CEPA as a dietary food for humans. Still, additional investigations to confirm these properties are needed in vivo study.

\section{Data Availability}

The data used to support the findings of this study are included within the article.

\section{Conflicts of Interest}

The authors declare no conflict of interest.

\section{Acknowledgments}

The authors extend their appreciation to the Deputyship for Research \& Innovation, Ministry of Education, Saudi Arabia, for funding this research work through the project number (QU-IF-1-2-1). The authors also thank Qassim University for the technical support. The researchers would like to thank the Deanship of Scientific Research, Qassim University for funding the publication of this project.

\section{References}

[1] A. Jurj, C. Braicu, L. A. Pop, C. Tomuleasa, C. D. Gherman, and I. Berindan-Neagoe, "The new era of nanotechnology, an alternative to change cancer treatment," Drug Design, Development and Therapy, vol. Volume 11, pp. 2871-2890, 2017. 
[2] M. E. Davis, Z. G. Chen, and D. M. Shin, "Nanoparticle therapeutics: an emerging treatment modality for cancer," Nature Reviews. Drug Discovery, vol. 7, no. 9, pp. 771-782, 2008.

[3] S. E. M. Eltom, A. A. H. Abdellatif, H. Maswadeh et al., "The anti-inflammatory effect of a $\gamma$-Lactone isolated from ostrich oil of Struthio camelus (Ratite) and its formulated nanoemulsion in formalin-induced paw edema," Molecules, vol. 26, no. 12, p. 3701, 2021.

[4] B. Aslan, B. Ozpolat, A. K. Sood, and G. Lopez-Berestein, "Nanotechnology in cancer therapy," Journal of Drug Targeting, vol. 21, no. 10, pp. 904-913, 2013.

[5] S. S. Shankar, A. Rai, A. Ahmad, and M. Sastry, "Controlling the optical properties of lemongrass extract synthesized gold nanotriangles and potential application in infrared-absorbing optical coatings," Chemistry of Materials, vol. 17, no. 3, pp. 566-572, 2005.

[6] M. Bilal, T. Rasheed, H. M. N. Iqbal, H. Hu, W. Wang, and $\mathrm{X}$. Zhang, "Macromolecular agents with antimicrobial potentialities: a drive to combat antimicrobial resistance," International Journal of Biological Macromolecules, vol. 103, pp. 554-574, 2017.

[7] F. Wang, C. Li, J. Cheng, and Z. Yuan, "Recent advances on inorganic nanoparticle-based cancer therapeutic agents," International Journal of Environmental Research and Public Health, vol. 13, no. 12, p. 1182, 2016.

[8] A. A. H. Abdellatif, H. A. Mohammed, R. A. Khan et al., "Nano-scale delivery: a comprehensive review of nanostructured devices, preparative techniques, site-specificity designs, biomedical applications, commercial products, and references to safety, cellular uptake, and organ toxicity," Nanotechnology Reviews, vol. 10, no. 1, pp. 1493-1559, 2021.

[9] N. M. Elbaz, L. Ziko, R. Siam, and W. Mamdouh, "Core-shell silver/polymeric nanoparticles-based combinatorial therapy against breast cancer_in-vitro_," Scientific Reports, vol. 6, no. 1, p. 30729, 2016.

[10] A. Eatemadi, M. Darabi, L. Afraidooni et al., "Comparison, synthesis and evaluation of anticancer drug-loaded polymeric nanoparticles on breast cancer cell lines," Artif Cells Nanomed Biotechnol, vol. 44, no. 3, pp. 1008-1017, 2016.

[11] A. A. H. Abdellatif and A. F. Alsowinea, "Approved and marketed nanoparticles for disease targeting and applications in COVID-19," Nanotechnology Reviews, vol. 10, no. 1, pp. 1941-1977, 2021.

[12] A. A. H. Abdellatif, R. A. Khan, A. H. Alhowail et al., "Octreotide-conjugated silver nanoparticles for active targeting of somatostatin receptors and their application in a nebulized rat model," Nanotechnology Reviews, vol. 11, no. 1, pp. 266283, 2022.

[13] T. Akther, Vabeiryureilai Mathipi, Nachimuthu Senthil Kumar, M. Davoodbasha, and H. Srinivasan, "Fungal-mediated synthesis of pharmaceutically active silver nanoparticles and anticancer property against A549 cells through apoptosis," Environmental Science and Pollution Research International, vol. 26, no. 13, pp. 13649-13657, 2019.

[14] M. Buttacavoli, N. N. Albanese, G. Di Cara et al., "Anticancer activity of biogenerated silver nanoparticles: an integrated proteomic investigation," Oncotarget, vol. 9, no. 11, pp. 96859705, 2018.

[15] E. S. Al-Sheddi, N. N. Farshori, M. M. Al-Oqail et al., "Anticancer potential of green synthesized silver nanoparticles using extract of Nepeta deflersiana against human cervical cancer cells (HeLA)," Bioinorganic Chemistry and Applications, vol. 2018, Article ID 9390784, 12 pages, 2018.

[16] S. I. Kaba and E. M. Egorova, "In vitro studies of the toxic effects of silver nanoparticles on HeLa and U937 cells," Nanotechnology, Science and Applications, vol. 8, pp. 19-29, 2015.

[17] D. S. W. Tan, U. N. Lassen, C. M. Albert et al., "Larotrectinib efficacy and safety in TRK fusion cancer: an expanded clinical dataset showing consistency in an age and tumor agnostic approach," Annals of Oncology, vol. 29, p. ix23, 2018.

[18] D. Goli, "Editor's note 2019," Indian Journal of Pharmaceutical Sciences, vol. 81, no. 1, 2019.

[19] S. Sarkar and V. Kotteeswaran, "Green synthesis of silver nanoparticles from aqueous leaf extract of pomegranate (Punica granatum) and their anticancer activity on human cervical cancer cells," Advances in Natural Sciences: Nanoscience and Nanotechnology, vol. 9, no. 2, 2018.

[20] A. Singh and K. Kaur, "Biological and physical applications of silver nanoparticles with emerging trends of green synthesis," in Engineered Nanomaterials-Health and Safety, Amazon.com, 2020.

[21] M. Behravan, A. Hossein Panahi, A. Naghizadeh, M. Ziaee, R. Mahdavi, and A. Mirzapour, "Facile green synthesis of silver nanoparticles using Berberis vulgaris leaf and root aqueous extract and its antibacterial activity," International Journal of Biological Macromolecules, vol. 124, pp. 148-154, 2019.

[22] R. A. Ismail, G. M. Sulaiman, M. H. Mohsin, and A. H. Saadoon, "Preparation of silver iodide nanoparticles using laser ablation in liquid for antibacterial applications," IET Nanobiotechnology, vol. 12, no. 6, pp. 781-786, 2018.

[23] S. A. Masurkar, P. R. Chaudhari, V. B. Shidore, and S. P. Kamble, "Rapid biosynthesis of silver nanoparticles using Cymbopogan citratus (lemongrass) and its antimicrobial activity," Nano-Micro Letters, vol. 3, no. 3, pp. 189-194, 2011.

[24] A. A. H. Abdellatif, "Silver nanoparticle-coated ethyl cellulose inhibits tumor necrosis factor- $\alpha$ of breast cancer cells," Drug Design, Development and Therapy, vol. 15, pp. 2035-2046, 2021.

[25] A. A. H. Abdellatif, H. N. H. Alturki, and H. M. Tawfeek, "Different cellulosic polymers for synthesizing silver nanoparticles with antioxidant and antibacterial activities," Scientific Reports, vol. 11, no. 1, p. 84, 2021.

[26] A. K. Mittal, Y. Chisti, and U. C. Banerjee, "Synthesis of metallic nanoparticles using plant extracts," Biotechnology Advances, vol. 31, no. 2, pp. 346-356, 2013.

[27] R. Bhanumathi, K. Vimala, K. Shanthi, R. Thangaraj, and S. Kannan, "Bioformulation of silver nanoparticles as berberine carrier cum anticancer agent against breast cancer," New Journal of Chemistry, vol. 41, no. 23, pp. 14466-14477, 2017.

[28] A. M. Grumezescu, Nanobiomaterials in Cancer Therapy: Applications of Nanobiomaterials, Elsevier/WA, William Andrew is an imprint of Elsevier, Amsterdam; Boston, 2016.

[29] R. Krishnasamy Sekar, A. Sridhar, B. Perumalsamy, D. B. Manikandan, and T. Ramasamy, "In vitro antioxidant, antipathogenicity and cytotoxicity effect of silver nanoparticles fabricated by onion (Allium cepa L.) peel extract," BioNanoScience, vol. 10, no. 1, pp. 235-248, 2020.

[30] E. Block, "The chemistry of garlic and onions," Scientific American, vol. 252, no. 3, pp. 114-118, 1985.

[31] V. Benitez, E. Molla, M. A. Martin-Cabrejas et al., "Characterization of industrial onion wastes (Allium cepa L.): dietary fibre and bioactive compounds," Plant Foods for Human Nutrition, vol. 66, no. 1, pp. 48-57, 2011. 
[32] R. Mete, M. Oran, B. Topcu et al., "Protective effects of onion (Allium cepa) extract against doxorubicin-induced hepatotoxicity in rats," Toxicology and Industrial Health, vol. 32, no. 3, pp. 551-557, 2016.

[33] G. Kaur, V. Gupta, A. Christopher, and P. Bansal, "Antioxidant potential of most commonly used vegetable-onion (Allium cepa L.)," Journal of Complementary and Alternative Medical Research, vol. 1, no. 1, pp. 1-5, 2016.

[34] L. Liguori, R. Califano, D. Albanese, F. Raimo, A. Crescitelli, and M. Di Matteo, "Chemical composition and antioxidant properties of five white onion (Allium cepa L.) landraces," Journal of Food Quality, vol. 2017, 9 pages, 2017.

[35] D. Prakash, B. N. Singh, and G. Upadhyay, "Antioxidant and free radical scavenging activities of phenols from onion (Allium cepa)," Food Chemistry, vol. 102, no. 4, pp. 13891393, 2007.

[36] W. S. Lee, S. M. Yi, J. W. Yun et al., "Polyphenols isolated from Allium cepa L. induces apoptosis by induction of p53 and suppression of Bcl-2 through inhibiting PI3K/Akt signaling pathway in AGS human cancer cells," Journal of Cancer Prevention, vol. 19, no. 1, pp. 14-22, 2014.

[37] Y. Wang, W. X. Tian, and X. F. Ma, "Inhibitory effects of onion (Allium cepa L.) extract on proliferation of cancer cells and adipocytes via inhibiting fatty acid synthase," Asian Pacific Journal of Cancer Prevention, vol. 13, no. 11, pp. 5573-5579, 2012.

[38] H. Xiao and K. L. Parkin, "Isolation and identification of potential cancer chemopreventive agents from methanolic extracts of green onion (Allium cepa)," Phytochemistry, vol. 68, no. 7, pp. 1059-1067, 2007.

[39] M. S. Jabir, A. A. Hussien, G. M. Sulaiman et al., "Green synthesis of silver nanoparticles fromEriobotrya japonicaextract: a promising approach against cancer cells proliferation, inflammation, allergic disorders and phagocytosis induction," Artificial Cells, Nanomedicine, and Biotechnology, vol. 49, no. 1, pp. 48-60, 2021.

[40] A. Akinboro, K. B. Mohamed, M. Z. Asmawi, S. F. Sulaiman, and O. A. Sofiman, "Antioxidants in aqueous extract of Myristica fragrans (Houtt.) suppress mitosis and cyclophosphamide-induced chromosomal aberrations in Allium cepa L. cells," Journal of Zhejiang University. Science. $B$, vol. 12, no. 11, pp. 915-922, 2011.

[41] E. Z. Gomaa, "Antimicrobial, antioxidant and antitumor activities of silver nanoparticles synthesized by Allium cepa extract: a green approach," Journal, Genetic Engineering \& Biotechnology, vol. 15, no. 1, pp. 49-57, 2017.

[42] A. A. H. Abdellatif, Z. Rasheed, A. H. Alhowail et al., "Silver citrate nanoparticles inhibit PMA-induced TNF $\alpha$ expression via deactivation of NF- $\kappa \mathrm{B}$ activity in human cancer cell-lines, MCF-7," International Journal of Nanomedicine, vol. Volume 15, pp. 8479-8493, 2020.

[43] A. A. H. Abdellatif, "A plausible way for excretion of metal nanoparticlesviaactive targeting," Drug Development and Industrial Pharmacy, vol. 46, no. 5, pp. 744-750, 2020.

[44] A. A. H. Abdellatif, M. A. Ibrahim, M. A. Amin et al., "Cetuximab conjugated with octreotide and entrapped calcium alginate-beads for targeting somatostatin receptors," Scientific Reports, vol. 10, no. 1, p. 4736, 2020.

[45] A. A. H. Abdellatif, S. H. Alawadh, A. Bouazzaoui, A. H. Alhowail, and H. A. Mohammed, "Anthocyanins rich pomegranate cream as a topical formulation with anti-aging activity," The
Journal of Dermatological Treatment, vol. 32, no. 8, pp. $983-$ 990, 2021.

[46] L. M. Aroua, H. R. Almuhaylan, F. M. Alminderej et al., "A facile approach synthesis of benzoylaryl benzimidazole as potential $\alpha$-amylase and $\alpha$-glucosidase inhibitor with antioxidant activity," Bioorganic Chemistry, vol. 114, article 105073, 2021.

[47] H. A. Mohammed, M. S. Al-Omar, S. A. A. Mohammed, M. S. A. Aly, A. N. A. Alsuqub, and R. A. Khan, "Drying induced impact on composition and oil quality of rosemary herb, Rosmarinus officinalis Linn," Molecules, vol. 25, no. 12, p. 2830, 2020.

[48] I. F. Benzie and J. J. Strain, "The ferric reducing ability of plasma (FRAP) as a measure of "antioxidant power": the FRAP assay," Analytical Biochemistry, vol. 239, no. 1, pp. 70-76, 1996.

[49] Y. Onuki, Y. Machida, T. Yokawa, C. Seike, S. Sakurai, and K. Takayama, "Magnetic resonance imaging study on the physical stability of menthol and diphenhydramine cream for the treatment of chronic kidney disease-associated pruritus," Chemical and Pharmaceutical Bulletin, vol. 63, no. 6, pp. 457-462, 2015.

[50] A. Ghadimi, R. Saidur, and H. S. C. Metselaar, "A review of nanofluid stability properties and characterization in stationary conditions," International Journal of Heat and Mass Transfer, vol. 54, no. 17-18, pp. 4051-4068, 2011.

[51] O. Al-Obeed, A. S. El-Obeid, S. Matou-Nasri et al., "Herbal melanin inhibits colorectal cancer cell proliferation by altering redox balance, inducing apoptosis, and modulating MAPK signaling," Cancer Cell International, vol. 20, no. 1, p. 126, 2020.

[52] I. Fernando, T. Qian, and Y. Zhou, "Long term impact of surfactants \& polymers on the colloidal stability, aggregation and dissolution of silver nanoparticles," Environmental Research, vol. 179, no. Part A, article 108781, 2019.

[53] M. Safaepour, A. R. Shahverdi, H. R. Shahverdi, M. R. Khorramizadeh, and A. R. Gohari, "Green synthesis of small silver nanoparticles using geraniol and its cytotoxicity against Fibrosarcoma-Wehi 164," Avicenna Journal of Medical Biotechnology, vol. 1, no. 2, pp. 111-115, 2009.

[54] K. Fuku, R. Hayashi, S. Takakura, T. Kamegawa, K. Mori, and H. Yamashita, "The synthesis of size- and color-controlled silver nanoparticles by using microwave heating and their enhanced catalytic activity by localized surface plasmon resonance," Angewandte Chemie (International Ed. in English), vol. 52, no. 29, pp. 7446-7450, 2013.

[55] C. M. Moraes, E. De Paula, A. H. Rosa, and L. F. Fraceto, "Physicochemical stability of poly(lactide-co-glycolide) nanocapsules containing the local anesthetic bupivacaine," Journal of the Brazilian Chemical Society, vol. 21, no. 6, pp. 9951000, 2010.

[56] E. D. Kaufman, J. Belyea, M. C. Johnson et al., "Probing protein adsorption onto mercaptoundecanoic acid stabilized gold nanoparticles and surfaces by quartz crystal microbalance and zeta-potential measurements," Langmuir, vol. 23, no. 11, pp. 6053-6062, 2007.

[57] J. Vieville, M. Tanty, and M. A. Delsuc, "Polydispersity index of polymers revealed by DOSY NMR," Journal of Magnetic Resonance, vol. 212, no. 1, pp. 169-173, 2011.

[58] S. Sunkar and C. V. Nachiyar, "Biogenesis of antibacterial silver nanoparticles using the endophytic bacterium Bacillus cereus isolated from Garcinia xanthochymus," Asian Pacific 
Journal of Tropical Biomedicine, vol. 2, no. 12, pp. 953-959, 2012.

[59] A. M. Awwad, N. M. Salem, and A. O. Abdeen, "Green synthesis of silver nanoparticles using carob leaf extract and its antibacterial activity," International Journal of Industrial Chemistry, vol. 4, no. 1, p. 29, 2013.

[60] R. Sathyavathi, M. B. Krishna, S. V. Rao, R. Saritha, and D. N. Rao, "Biosynthesis of silver nanoparticles using Coriandrum sativum leaf extract and their application in nonlinear optics," Advanced Science Letters, vol. 3, no. 2, pp. 138-143, 2010.

[61] I. Grigalius and V. Petrikaite, "Relationship between antioxidant and anticancer activity of trihydroxyflavones," Molecules, vol. 22, no. 12, p. 2169, 2017.

[62] S. Pirtarighat, M. Ghannadnia, and S. Baghshahi, "Green synthesis of silver nanoparticles using the plant extract of Salvia spinosa grown in vitro and their antibacterial activity assessment," Journal of Nanostructure in Chemistry, vol. 9, no. 1, pp. 1-9, 2019.

[63] J. Kale, E. J. Osterlund, and D. W. Andrews, "BCL-2 family proteins: changing partners in the dance towards death," Cell Death and Differentiation, vol. 25, no. 1, pp. 65-80, 2018.

[64] B. A. Carneiro and W. S. El-Deiry, "Targeting apoptosis in cancer therapy," Nature Reviews. Clinical Oncology, vol. 17, no. 7, pp. 395-417, 2020.

[65] K. Ghosal, S. Ghosh, D. Ghosh, and K. Sarkar, "Natural polysaccharide derived carbon dot based in situ facile green synthesis of silver nanoparticles: synergistic effect on breast cancer," International Journal of Biological Macromolecules, vol. 162, pp. 1605-1615, 2020.

[66] R. Nishanthi, S. Malathi, and P. Palani, "Green synthesis and characterization of bioinspired silver, gold and platinum nanoparticles and evaluation of their synergistic antibacterial activity after combining with different classes of antibiotics," Materials Science and Engineering: C, vol. 96, pp. 693-707, 2019.

[67] P. Tippayawat, N. Phromviyo, P. Boueroy, and A. Chompoosor, "Green synthesis of silver nanoparticles in aloe vera plant extract prepared by a hydrothermal method and their synergistic antibacterial activity," PeerJ, vol. 4, article e2589, 2016.

[68] P. Belteky, A. Ronavari, D. Zakupszky et al., "Are smaller nanoparticles always better? Understanding the biological effect of size-dependent silver nanoparticle aggregation under biorelevant conditions," International Journal of Nanomedicine, vol. Volume 16, pp. 3021-3040, 2021.

[69] X. Wang, X. Cui, Y. Zhao, and C. Chen, "Nano-bio interactions: the implication of size-dependent biological effects of nanomaterials," Science China. Life Sciences, vol. 63, no. 8, pp. 1168-1182, 2020.

[70] M. Busila, A. Tabacaru, V. Mussat et al., "Size-dependent biological activities of fluorescent organosilane-modified zinc oxide nanoparticles," Journal of Biomedical Nanotechnology, vol. 16, no. 2, pp. 137-152, 2020.

[71] M. S. Jabir, Y. M. Saleh, G. M. Sulaiman et al., "Green synthesis of silver nanoparticles using annona muricata extract as an inducer of apoptosis in cancer cells and inhibitor for NLRP3 inflammasome via enhanced autophagy," Nanomaterials, vol. 11, no. 2, p. 384, 2021. 